\title{
Early and Late-Term Follow-Up Results of Patients Diagnosed with Aortic Aneurysm or Aortic Dissection with Aortic Regurgitation Undergoing Aortic Valve Repair or Valve-Sparing Aortic Surgery
}

Görkem Yiğit', MD; Anıl Özen", MD; Ferit Çetinkaya', MD; Ertekin Utku Ünal', MD; Hakki Zafer İşcan', MD; Cemal Levent Birincioğlu', MD, PhD; Ahmet Sarıtaş ${ }^{1}, \mathrm{MD}, \mathrm{PhD}$

DOI: $10.21470 / 1678-9741-2020-0133$

\begin{abstract}
Introduction: Valve-reimplantation and remodelling techniques used in aortic reconstruction provide successful early, mid, and longterm results. We present our early and late-term experience with 110 patients with aortic regurgitation (AR) who underwent aortic valve repair (AVr) or valve-sparing aortic root surgeries (VSARS) due to aortic dissection or aortic aneurysm.

Methods: Nine hundred eighty-two patients who underwent aneurysm or dissection surgery and aortic valve surgery between April 1997 and January 2017 were analysed using the patient database. A total of $\mathbf{1 1 0}$ patients with AR who underwent $A V r$ or VSARS due to aortic dissection or aortic aneurysm were included in the study.

Results: In the postoperative period, a decrease was observed in AR compared to the preoperative period $(P<0.001)$; there was an increase in postoperative ejection fraction (EF) compared to
\end{abstract}

the preoperative values $(P<0.005)$ and a significant decrease in postoperative left ventricle diameters compared to the preoperative values $(P<0.001)$. Kaplan-Meier analysis revealed one, two, four, and five-year freedom from moderate-severe AR as $95 \%, 91 \%, 87 \%$, and $70 \%$, respectively. Freedom from reoperation in one, two, and five years were $97.9 \%, 93.6 \%$, and $81 \%$, respectively. Eight patients (7.4\%) underwent AVr during follow-up. Out of the remaining 100 patients, $13(12 \%)$ had minimum $A R, 52(48 \%)$ had $1^{\text {st }}-2^{\text {nd }}$ degree $A R$, and 35 (32\%) had $2^{\text {nd }}-3^{\text {rd }}$ degree AR during follow-up.

Conclusion: For the purpose of maintaining the native valve tissue, preserving the EF and the left ventricular end-diastolic diameter, valve-sparing surgeries should be preferred for appropriate patients.

Keywords: Aortic Valve Insufficiency. Aortic Aneurysm. Aortic Valve. Heart Ventricles. Stroke Volume. Aneurysm, Dissecting. Postoperative Period. Replantation.

\begin{tabular}{llll}
\hline \multicolumn{2}{l}{ Abbreviations, acronyms \& symbols } & & \\
\hline AR & = Aortic regurgitation & INR & = International Normalization Ratio \\
ASCP & = Antegrade selective cerebral perfusion & LVEDD & $=$ Left ventricular end-diastolic diameter \\
AVr & $=$ Aortic valve repair & MFS & $=$ Marfan syndrome \\
AVR & $=$ Aortic valve replacement & NYHA & $=$ New York Heart Association \\
BAV & $=$ Bicuspid aortic valve & SCG & $=$ Supracoronary graft replacement \\
CHF & $=$ Chronic heart failure & SPSS & $=$ Statistical Package for the Social Sciences \\
COPD & $=$ Chronic obstructive pulmonary disease & STJ & $=$ Sinotubular junction \\
CPB & $=$ Cardiopulmonary bypass & VSARS & $=$ Valve-sparing aortic root surgery \\
CVA & $=$ Cerebrovascular accident & XCL & $=$ X-clamp \\
EF & $=$ Ejection fraction & & \\
& & & \\
\hline
\end{tabular}

\section{'Department of Cardiovascular Surgery, Ankara City Hospital, Ankara, Turkey.}

This study was carried out at the Department of Cardiovascular Surgery, Ankara City Hospital, Ankara, Turkey.
Correspondence Address:

Görkem Yiğit

(iD) https://orcid.org/0000-0002-9500-720X

Altınkuleler Sitesi, Altındağ

Sakarya Mahallesi, Yönü Sokak, Ankara, Turkey - Zip Code: 06080

E-mail: drgorkemyigit@gmail.com 


\section{INTRODUCTION}

Aortic valve reconstruction techniques have been available since the late 1950s. However, poor surgical outcomes resulted in aortic valve replacement (AVR) being predominantly preferred until the 1990s. In the early 1990s, aortic valve-sparing operations were initiated under the leadership of David and Yacoub and became widespread in the light of their long-term successful results ${ }^{[1]}$. Valve-reimplantation and remodelling techniques used in aortic reconstruction provide successful early, mid, and long-term results when applied to appropriate patients by an experienced surgical team.

Valve-protective surgery aims to preserve the patient's native valve and prevent prosthetic valve replacement surgery. In patients undergoing mechanical valve replacement, catastrophic complications such as valvular thrombosis and mechanical valve dysfunction due to ineffective coumadin use may occur. Furthermore, bleeding due to high International Normalization Ratio (INR) values and prosthetic valve endocarditis are amongst other significant complications. In addition, the possibility of lifethreatening conditions and complications related to mechanical valve replacement, such as patient-prosthetic valve mismatch, pannus, and paravalvular leak, require the use of valve repair and valve-sparing surgery ${ }^{[2]}$.

The aim of our study was to determine early and late survival, degree of postoperative aortic regurgitation (AR), the incidence of redo cases, and early and late postoperative complication rates in patients diagnosed with aortic aneurysm or aortic dissection with $A R$ undergoing aortic valve repair $(A V r)$ or valve-sparing aortic root surgery (VSARS).

\section{METHODS}

\section{Study Population}

Nine hundred eighty-two patients who underwent aortic valve surgery and aortic aneurysm or dissection surgery between April 1997 and January 2017 were analysed using the patient database (Sarus and Avicenna automation systems) and examined by scanning files from hospital archives. A total of 110 patients with AR who underwent AVr or VSARS due to aortic dissection or aortic aneurysm were included in the study. Patients with AVR and patients without intervention of the aortic valve were excluded from the study.

There were only two mortalities in 110 patients (one intraoperatively and one at the fifth postoperative hour). Hence, a total of 108 patients were followed up. Preoperative data regarding age, sex, presence of Marfan syndrome (MFS), echocardiographic findings (aneurysm diameter, AR or stenosis degree, left ventricular end-diastolic diameter [LVEDD], ejection fraction $[E F])$, and data about other valve pathologies were obtained.

Intraoperative data regarding $\mathrm{x}$-clamp (XCL) time, cardiopulmonary bypass (CPB) time, antegrade selective cerebral perfusion (ASCP) time, cooling degree, type of operation, need for inotropic support, and operative mortality data were collected.

In the postoperative period, early and late survival, mortality and morbidity rates, echocardiographic findings (AR or stenosis degree, LVEDDs, EF), incidence of being a redo case, causes of early and late mortality and morbidity, and postoperative complications were investigated. The minimum follow-up period was two months and the longest one was 108 months.

\section{Echocardiographic Assessment}

All patients underwent post-repair intraoperative transepicardial or transoesophageal echocardiographic analysis. Transthoracic echocardiography was performed for all patients prior to discharge and at regular intervals for living patients with native valve during the course of follow-up.

\section{Statistical Analysis}

All data were analysed using the Statistical Package for the Social Sciences (SPSS) software (SPSS Inc., Chicago, United States of America), version 15.0. The normal distribution of the variables was evaluated visually, using histograms and probability graphs, and analytically, using the Kolmogorov-Smirnov and Shapiro-Wilk tests. Normally distributed continuous variables were expressed in means and standard deviation whereas non-normally distributed continuous variables were presented using median and interquartile range values. Data on categorical variables were expressed in numbers and percentages. Preopereative and postoperative data was analysed using the Wilcoxon test. The Kaplan-Meier was used to evaluate freedom from mediumsevere AR and freedom from reoperation. A different log-rank analysis was preferred to study the effect of valve-sparing surgery on survival. P-values $<0.05$ were considered statistically significant.

\section{RESULTS}

A total of 108 patients with AR who underwent AVr or VSARS due to aortic dissection or aortic aneurysm were included in the study. Twenty of these patients had aortic dissection (18.5\%), seven (6.4\%) had MFS, and five (4.6\%) had bicuspid aortic valve (BAV) (Table 1).

The mean follow-up of our study was 25.29 \pm 24.81 (2108) months. Seventy-two (66.7\%) of the patients were male. There were only two mortalities out of 110 patients (one intraoperatively and one at the fifth postoperative hour). Hence, a total of 108 patients were followed up. Aortic valve intervention and supracoronary graft replacement (SCG) were performed in 94 patients (87\%); aortic valve intervention and remodelling were performed in 14 patients (13\%) (Table 1).

The mean age of the patients included in our study was $57.25 \pm 13.20$ years. The youngest patient was a 24-year-old female with AR and ascending aortic aneurysm who underwent AVr and SCG. The oldest patient was an 82-year-old woman who underwent AVr, SCG, and two-vessel coronary bypass surgery for AR with coronary artery disease and ascending aortic aneurysm.

Mean operative time was 333.36 13.20 (180-780) minutes; mean CPB duration was $126.16 \pm 48.66$ (54-352) minutes, and mean XCL duration was 82.28 \pm 32.24 (32-169) minutes. Only 42 patients (39.8\%) underwent ASCP (Table 2).

Postoperative data including the need for inotropic support, eryhrocyte suspension, and fresh frozen plasma are given in Table 3. 
Table 1. Preoperative patients' characteristics.

\begin{tabular}{|c|c|c|}
\hline \multirow{2}{*}{$\operatorname{Sex}(N=108)$} & Female & $36(33.3 \%)$ \\
\hline & Male & $72(66.7 \%)$ \\
\hline \multicolumn{2}{|l|}{ Age (years) } & $57.25 \pm 13.20(20-82)$ \\
\hline \multicolumn{2}{|l|}{ Hypertension $(\mathrm{N}=108)$} & $72(66.6 \%)$ \\
\hline \multicolumn{2}{|c|}{ Diabetes mellitus ( $\mathrm{N}=108)$} & $12(11.1 \%)$ \\
\hline \multicolumn{2}{|l|}{ Hyperlipidemia (N=108) } & $15(13.8 \%)$ \\
\hline \multicolumn{2}{|l|}{ History of CVA ( $\mathrm{N}=108)$} & $6(5.5 \%)$ \\
\hline \multicolumn{2}{|c|}{ Chronic kidney disease $(\mathrm{N}=108)$} & $1(0.9 \%)$ \\
\hline \multicolumn{2}{|l|}{$\operatorname{COPD}(\mathrm{N}=108)$} & $5(4.6 \%)$ \\
\hline \multicolumn{2}{|c|}{ Marfan syndrome $(\mathrm{N}=108)$} & $7(6.4 \%)$ \\
\hline \multirow{4}{*}{$\begin{array}{l}\text { CHF NYHA class } \\
(\mathrm{N}=108)\end{array}$} & Class I & $37(34.3 \%)$ \\
\hline & Class $\|$ & $34(31.5 \%)$ \\
\hline & Class III & $28(25.9 \%)$ \\
\hline & Class IV & $9(8.3 \%)$ \\
\hline \multirow{2}{*}{$\begin{array}{l}\text { Rhythm } \\
(\mathrm{N}=108)\end{array}$} & Sinus rhythm & $106(98.1 \%)$ \\
\hline & Atrial fibrillation & $2(1.8 \%)$ \\
\hline \multirow{2}{*}{$\begin{array}{l}\text { Operation type } \\
(\mathrm{N}=108)\end{array}$} & Urgent & $20(18.5 \%)$ \\
\hline & Elective & $88(81.5 \%)$ \\
\hline \multirow{3}{*}{$\begin{array}{l}\text { Patients' diagnosis } \\
(\mathrm{N}=108)\end{array}$} & Type A aortic dissection & $20(18.5 \%)$ \\
\hline & Aortic regurgitation and ascending aortic aneurysm & $84(77.7 \%)$ \\
\hline & Aortic regurgitation and ascending aortic aneurysm with arcus aortic aneurysm & $4(3.7 \%)$ \\
\hline \multicolumn{2}{|l|}{ Bicuspid valve } & $5(4.6 \%)$ \\
\hline \multirow{2}{*}{$\begin{array}{l}\text { Operative procedure } \\
(\mathrm{N}=108)\end{array}$} & SCG + aortic valve intervention & $94(87 \%)$ \\
\hline & Sinus remodelling + aortic valve intervention & $14(13 \%)$ \\
\hline \multirow{3}{*}{$\begin{array}{l}\text { Additional surgical } \\
\text { procedure performed } \\
\text { on the aortic valve }\end{array}$} & Resuspension & $74(68.5 \%)$ \\
\hline & Plication & $25(23.1 \%)$ \\
\hline & Commissurotomy & $9(8.3 \%)$ \\
\hline \multirow{3}{*}{$\begin{array}{l}\text { Additional surgical } \\
\text { procedure } \\
(\mathrm{N}=21)\end{array}$} & Coronary artery bypass grafting & $17(15.7 \%)$ \\
\hline & Mitral valve replacement & $4(3.7 \%)$ \\
\hline & Total arcus replacement & $10(9.2 \%)$ \\
\hline
\end{tabular}

$\mathrm{CHF}=$ chronic heart failure; $\mathrm{COPD}=$ chronic obstructive pulmonary disease; $\mathrm{CVA}=$ cerebrovascular accident; NYHA=New York Heart Association; SCG=supracoronary graft replacement

In the postoperative period, 13 patients (12\%) underwent revision for tamponade and six patients (5.6\%) underwent revision for bleeding. Sixteen of these patients belonged to the SCG and AVr group, whereas three belonged to the remodelling and $\mathrm{AVr}$ group. Stroke developed in five patients (4.6\%), pneumonia in one patient, mediastinitis in one patient $(0.9 \%)$, and renal failure in one patient (0.9\%). Eight patients $(7.4 \%)$ underwent AVR during follow-up.
Eight patients (7.4\%) underwent AVR during follow-up. One, two, and five-year freedom from reoperation were $97.9 \%, 93.6 \%$, and $81 \%$, respectively (Figure 1). Three patients who had undergone SCG and $A V r$ with preoperative $2^{\text {nd }}$ degree and postoperative $3^{\text {rd }}$ degree of $A R$, underwent $A V R$ at the $57^{\text {th }}, 60^{\text {th }}$, and $64^{\text {th }}$ postoperative months; two patients who had undergone SCG and AVr with preoperative $3^{\text {rd }}$ to $4^{\text {th }}$ and $3^{\text {rd }}$ degree and postoperative $3^{\text {rd }}$ to $4^{\text {th }}$ degree of $A R$ underwent AVR at the $20^{\text {th }}$ and $24^{\text {th }}$ postoperative months; one 
Table 2. Intraoperative variables.

\begin{tabular}{l|l|c}
\hline Operation time (min) & & $333.36 \pm 13.20(180-780)$ \\
\hline XCL time (min) & & $82.28 \pm 32.24(32-169)$ \\
\hline CPB time (min) & & $126.16 \pm 48.66(54-352)$ \\
\hline ASCP time (min) & & $20.98 \pm 13.60(8-68)$ \\
\hline \multirow{2}{*}{ ASCP (min) } & Applied & $42(38.9 \%)$ \\
\cline { 2 - 3 } & Unapplied & $66(61.1 \%)$ \\
\hline Cooling degree $\left({ }^{\circ} \mathbf{C}\right)$ & & $27.74 \pm 2.03(19-34)$ \\
\hline
\end{tabular}

$\mathrm{ASCP}=$ antegrade selective cerebral perfusion; $\mathrm{CPB}=$ cardiopulmonary bypass; $\mathrm{XCL}=\mathrm{x}$-clamp

Table 3. Postoperative variables.

\begin{tabular}{l|l|c}
\hline \multirow{2}{*}{ Inotropic administration (N=108) } & None & $37(34.3 \%)$ \\
\cline { 2 - 3 } & Single & $24(22.2 \%)$ \\
\cline { 2 - 3 } Drainage (cc) & Two & $47(43.5 \%)$ \\
\hline Intubation time (h) & & $910.93 \pm 726.67(50-4250)$ \\
\hline Erythrocyte suspension transfusion (Unit) & & $18.62 \pm 41.04(5-400)$ \\
\hline Fresh frozen plasma transfusion (Unit) & & $1.42 \pm 2.30(1-18)$ \\
\hline
\end{tabular}

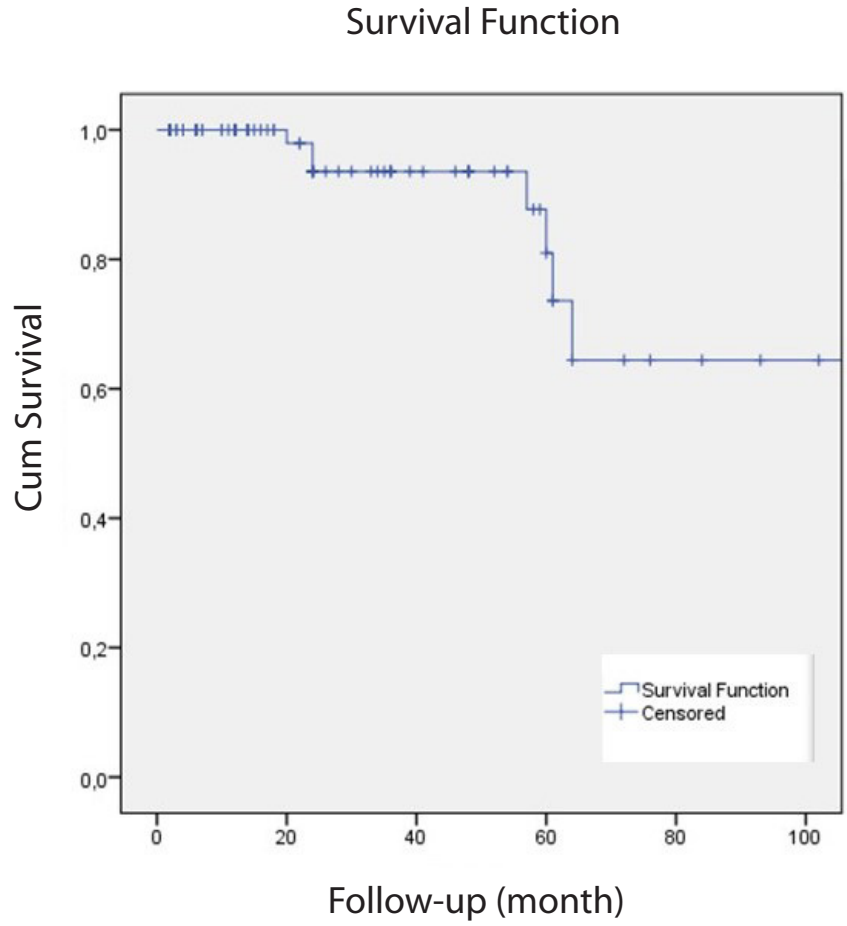

Fig. 1 - Kaplan-Meier curve for freedom from reoperation. patient who had undergone Yacoub procedure with preoperative $1^{\text {st }}$ degree and postoperative $3^{\text {rd }}$ degree of AR underwent AVR at the $61^{\text {th }}$ postoperative month; and two patients who had undergone SCG and AVr due to acute aortic dissection with preoperative $1^{\text {st }}$ to $2^{\text {nd }}$ degree and postoperative $3^{\text {rd }}$ degree of AR underwent AVR at the $24^{\text {th }}$ and $108^{\text {th }}$ postoperative months (Table 4).

When the $A R, E F$, and diastolic ventricular diameters were compared in the preoperative and postoperative period, the differences were statistically significant. In the postoperative period, a decrease was observed in AR compared to the preoperative period $(P<.001)$; there was an increase in postoperative $E F$ compared to preoperative values $(P<.005)$ and significant decrease in postoperative left ventricle diameters compared to preoperative values $(P<.001)$ (Table 5). Kaplan-Meier analysis revealed one, two, four, and five-year freedom from moderate-severe AR as 95\%, 91\%, $87 \%$, and $70 \%$, respectively (Figure 2).

When the remodelling and non-remodelling groups were compared, no difference was found between the two methods in terms of freedom from AR ( $P=.832)$ (Figure 3 ).

Out of 100 remaining patients, 13 (12\%) had minimum AR, 52 (48\%) had $1^{\text {st }}-2^{\text {nd }}$ degree $A R$, and 35 (32\%) had $2^{\text {nd }}-3^{\text {rd }}$ degree $A R$ during follow-up.

\section{DISCUSSION}

Aortic valve reconstruction techniques have been available since the late 1950s. However, poor surgical outcomes resulted 
Table 4. Patients undergoing aortic valve replacement.

\begin{tabular}{|c|c|c|c|c|}
\hline Patient & Operation type & Preop. AR & Postop. AR & $\begin{array}{c}\text { Follow-up } \\
\text { period (month) }\end{array}$ \\
\hline 1 & SCG and aortic valve plication & 2 & 3 & 57 \\
\hline 2 & SCG and aortic valve resuspension & 2 & 3 & 60 \\
\hline 3 & SCG and aortic valve resuspension (bicuspid) & 2 & 3 & 64 \\
\hline 4 & SCG and aortic valve resuspension & $3 / 4$ & $3 / 4$ & 20 \\
\hline 5 & SCG and aortic valve resuspension & 3 & $3 / 4$ & 24 \\
\hline 6 & Aortic remodelling and aortic valve plication & 1 & 3 & 61 \\
\hline 7 & SCG and aortic valve resuspension (type 1 dissection) & $1 / 2$ & 3 & 24 \\
\hline 8 & SCG and aortic valve resuspension (type 1 dissection) & $1 / 2$ & 3 & 108 \\
\hline
\end{tabular}

$\mathrm{AR}=$ aortic regurgitation; $\mathrm{SCG}=$ supracoronary graft replacement

Table 5. Postoperative echocardiographic data.

\begin{tabular}{l|c|c|c}
\hline & Preoperative & Postoperative & $P$-value \\
\hline AR & $2.05 \pm 0.61(1-3.5)$ & $1.41 \pm 0.78(0-3)$ & $<0.001$ \\
\hline EF & $52.71 \pm 8.01(20-65)$ & $54.45 \pm 7.49(23-69)$ & $<0.005$ \\
\hline LVEDD & $5.25 \pm 0.76(4-8.2)$ & $4.97 \pm 0.64(3.9-7.4)$ & $<0.001$ \\
\hline
\end{tabular}

$\mathrm{AR}=$ aortic regurgitation; $\mathrm{EF}=$ ejection fraction; $\mathrm{LVEDD}=$ left ventricular end-diastolic diameter

\section{Survival Function}

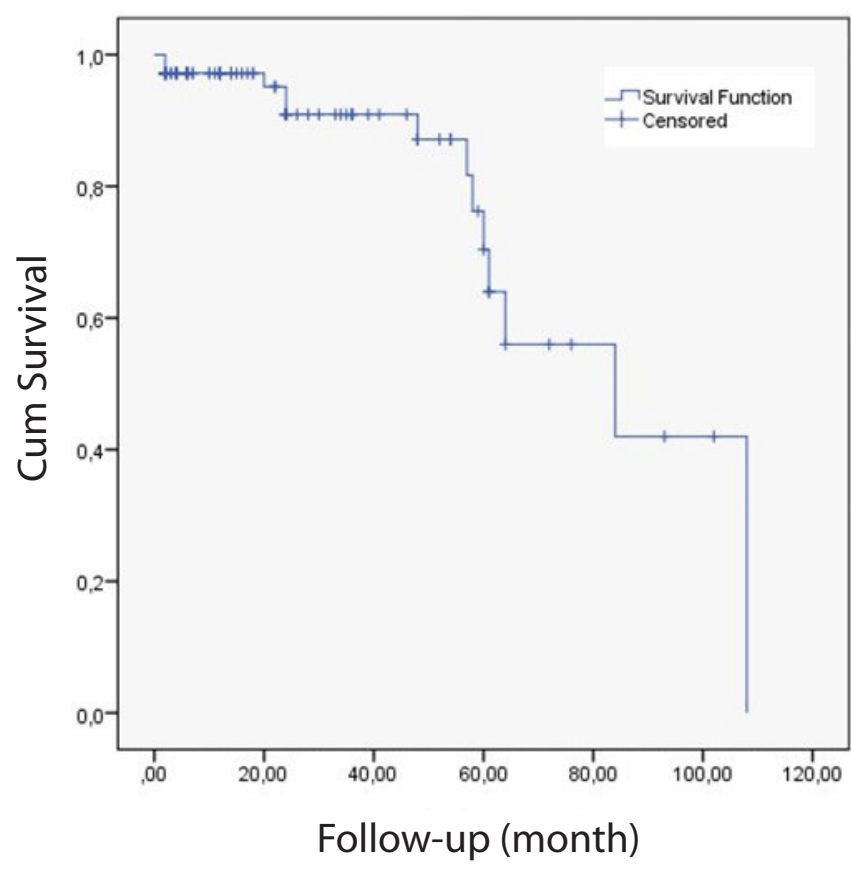

Fig. 2 - Kaplan-Meier curve for freedom from aortic regurgitation.

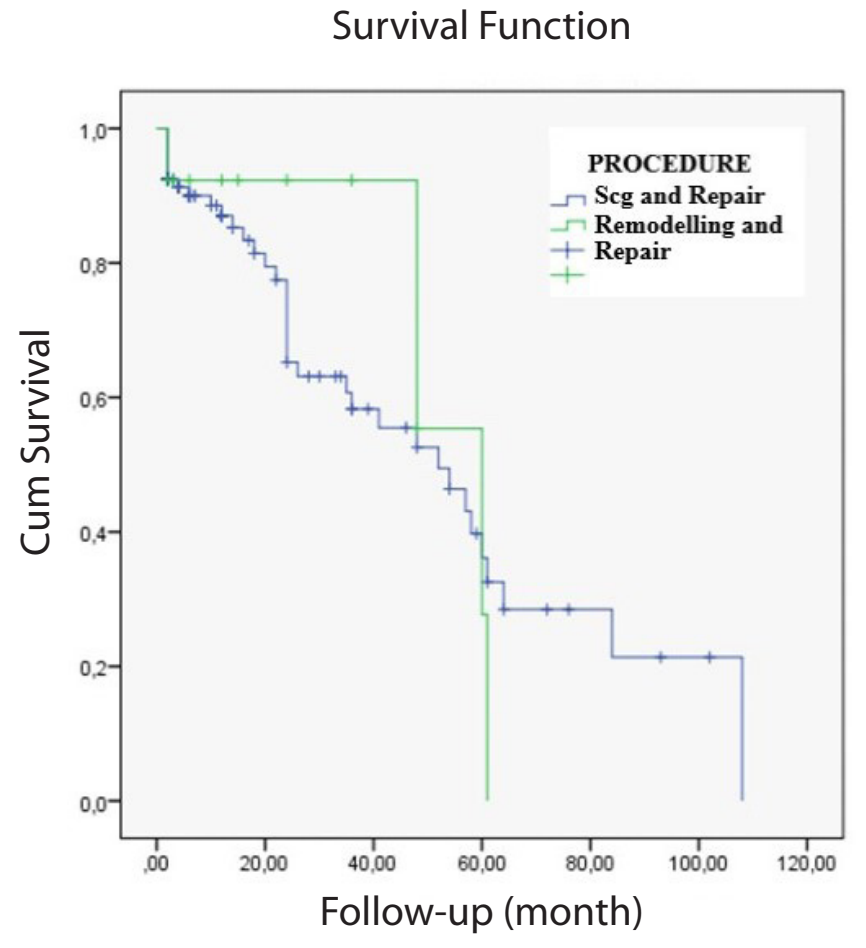

Fig. 3 - Kaplan-Meier comparison of aortic regurgitation in the remodelling and non-remodelling groups. SCG=supracoronary graft replacement 
in AVR being predominantly preferred until the 1990s. Valvesparing operations gained accelaration after the 1990s due to high complication rates. Bleeding rates following mechanical valve replacement after 10 an 20 years are 16\% and 61\%, respectively ${ }^{[3]}$, and thromboembolic complication rates after 10 and 20 years were shown as $10 \%$ and $24 \%$, respectively ${ }^{[3]}$. In addition, another major issue for this patient population is the economical burden caused by INR follow-up.

Bearing all the aforementioned disadvantages, interest in valve-sparing operations are growing. Benthall and its modifications have been accepted as golden standart ${ }^{[1,4,5]}$ for the surgical treatment of aortic root pathologies. Nevertheless, VSARS have become widely performed, due to successful longterm outcomes of these operations pioneered by David and Yacoub at the early $1990 \mathrm{~s}^{[1]}$. Valve-sparing reimplantation and remodelling techniques used in aortic reconstruction possess successful short and long-term results, when applied to the appropriate patients by experienced surgical teams and should be considered primarily for patients with annuloaortic ectasia ${ }^{[2]}$. All the operations in this series were perfomed by several experienced surgeons and the early and long-term results are satisfactory.

There are few studies on isolated AVr in the literature. Freedom from reoperation rates were displayed as $95 \%$ in five years for AR resulting from prolapsus ${ }^{[6,7]}$. Aicher et al. shared their successful, long-term follow-up results of 15 years. They performed isolated AVr in 1083 patients between 1999 and 2015; 583 (54\%) of these patients had tricuspid valves. Freedom from reintervention for tricuspid valves and bicuspid valves in five, 10, and 15 years were $94 \%$ and $84 \%, 81 \%$ and $90 \%, 78 \%$ and $71 \%$, respectively ${ }^{[6]}$. This result reveals that success of the repair of tricuspid valves is higher than that of the bicuspid ones. Furthermore, presence of enlarged annulus or sinotubular junction (STJ) in their series was one of the main risk factors for failed valve repair. Combining annulus reduction or STJ remodelling with AVr have improved the long-term results ${ }^{[8,9]}$.

VSARS is the choice of treatment for aortic root disease with functional leaflets, even though AR accompanies the pathology. However, AR is not always due to root dilatation and may require a combined treatment using cusp repair. Significant preoperative AR and cusp repair seem to be risk factors for poor prognosis following VSARS ${ }^{[10]}$. Nonetheless, Schafers et al. ${ }^{[1]]}$ applied an aggressive approach of combined leaflet prolapsus repair with VSARS and found no significance in operating times, mortality, and survival ${ }^{[11,12]}$. Besides this, Schafers preferred suture annuloplasy and Lansac used external ring annuluplasty in addition to reimplantation in order to stabilize the aortic root ${ }^{[13]}$.

In light of these developments, we retrospectively studied 108 patients, diagnosed with AR due to aortic aneurysm or dissection who underwent AVr or VSARS.

VSARS is usually preffered in young patients diagnosed with MFS and bicuspid aorta, aiming to stabilize the aortic annulus ${ }^{[14-16]}$. This study included 6.4\% MFS patients and 4.6\% congenital/ bicuspid valve patients. The mean age of the study participants was 57 years and they can be considered as relatively young.

Preservation of cuspis geometry is the most important element of valve-sparing surgery. Together with minimal central
$A R$, the final aim at the end of surgery should be no cuspis prolapsus and a coaptation height above the nadir of the aortic annulus.

There is a limited number of studies in the literature regarding the long-term outcome of patients undergoing VSARS. The ratios for survival after five and 10 years are $85-98.7 \%$ and $70-93.5 \%$, respectively ${ }^{[17-20]}$. No mortalities occured in our series.

Acute aortic dissection is a significant risk factor for early mortality following VSARS ${ }^{[18,21]}$. Nevertheless, there were no mortalities amongst the patients who underwent surgery due to acute aortic dissection in our study. In contrast, the study of Shresta et al. ${ }^{[18]}$ revealed six early deaths (four patients with diagnosis of aortic dissection) out of 126 patients. The total number of patients undergoing surgery due to acute aortic dissection was 21 in their study. Twenty (18.5\%) patients were operated with a diagnosis of acute type 1 aortic dissection in our study. All of these patients underwent SCG, AVR, and additional procedures. None of them underwent remodelling operations. There is no mortality during early, mid, and long-term followup of these patients. This may be explained by the fact that our patients with aortic dissection were not critically ill, malperfused, or comorbid patients as in the other mentioned studies.

Valve-sparing procedures are complex procedures requiring prolonged duration of $\mathrm{XCL}$ and $\mathrm{CPB}$ that may result in coagulopathies. Hence, the most common complication following such procedures is postoperative bleeding ${ }^{[21]}$. In the present study, following surgery, 13 (12\%) patients developed tamponade and six (5.6\%) patients underwent exploration due to bleeding. Five patients (4.6\%) developed cerebrovascular accident, one (0.9\%) had pneumonia, one (0.9\%) had mediastinitis, and one (0.9\%) had chronic renal failure.

The most significant problem after aortic valve-sparing and $A V r$ procedures is $A R$ and the need for consequent reoperation. Development of early AR following surgery is frequently due to technical failure ${ }^{[22]}$. None of the patients in the present study developed early AR. However, development of late AR mainly results from cusp degeneration and aortic root dilatation. David et al. ${ }^{[23]}$ announced five, 10, and 15-year freedom from midsevere AR rates as $98.3 \% \pm 3.5 \%, 92.9 \% \pm 6.5 \%$, and $89.4 \% \pm 12 \%$, respectively, in their study involving 296 patients. Furthermore, Coselli et al. ${ }^{[24]}$ shared their experience of 83 patients in 2014. They revealed two, four, six, and eight-year freedom from midsevere $A R$ rates as $94.8 \% \pm 2.6 \%, 81.1 \% \pm 5.3 \%, 77.8 \% \pm 6 \%$, and $73.9 \% \pm 6.9 \%$, respectively. The findings of the present study report the results of a maximum five-year period, evaluated by Kaplan-Meier analysis. Freedom from mid-severe AR rates are $95 \%, 91 \%, 87 \%$, and $70 \%$ in one, two, four, and five years, respectively, and the result of freedom from AR in five years is similar to the one of Coselli et al. ${ }^{[24]}$

Eight patients in the present study underwent AVR during the follow-up period; one patient at the postoperative $20^{\text {th }}$ month and two patients at the postoperative $24^{\text {th }}$ month. Consequently, these three patients underwent AVR approximately at the postoperative second year. Four patients underwent AVR at the postoperative $57^{\text {th }}, 60^{\text {th }}, 61^{\text {st }}$, and $64^{\text {th }}$ months, which means that they underwent valve replacement approximately at the postoperative fifth year. Finally, one patient underwent AVR at 
the postoperative $108^{\text {th }}$ month, which is nine years following SCG and AVr due to acute type 1 aortic dissection. Annular stabilization was performed only in a single 73-year-old male patient, who had undergone AVr and remodelling due to AR and ascending aortic aneurysm. His preoperative echocardiography reported $1^{\text {st }}$ degree AR and postoperative echocardiography reported $3^{\text {rd }}$ degree AR. He underwent AVR at the postoperative $61^{\text {th }}$ month. None of the patients undergoing AVR had annular dilatation. According to the operation notes, the cause of valve replacement was cusp degeneration. The rate of freedom from reoperation in 10 years is $81-98 \%$ in the literature ${ }^{[25]}$. Leipzig group stated the five-year freedom from reoperation rate as 95.9\% ${ }^{[26]}$. In addition, six patients out of 233 underwent AVR in the study of Kvitting et al. ${ }^{[19]}$ published in 2013. Their freedom from reoperation rates in five and 10 years were $98.0 \% \pm 1.2 \%$ and $92.2 \% \pm 3.6 \%$, respectively. In another study, David et al. ${ }^{[27]}$ (2013) reported that seven patients underwent reoperation out of 374 patients. Freedom from reoperation in their report in 10, 15 , and 20 years were $97.1 \%, 94.2 \%$, and $94.2 \%$, respectively. Our study revealed freedom from reoperation in one, two, and five years as $97.9 \%, 93.6 \%$, and $81 \%$, respectively. This result displays lower rates of freedom from reintervention compared to the aforementioned studies and maybe a result of presence of lower number of patients compared to other studies since our institute started performing valve-sparing operations 10 years later than the pioneering centers. Besides this, annular stabilization was applied only in a few patients and the operations were perfomed by six different surgeons.

Surgical approach for bicuspid valves is a topic much debated in the literature. Studies reveal worse outcomes for BAV compared to tricuspid ones, following valve-sparing operations ${ }^{[28]}$. A recent study by Shrestha et al. ${ }^{[29]}$ found high reoperation rate for patients with BAV (25\%) with $7.2 \pm 4.7$ years of follow-up. Their study revealed freedom from reoperation for patients with BAV as $68 \%$ in 10 years. However, Schafers et al. [30] displayed freedom from reoperation in five years as 97\%, for 173 patients undergoing AVr. Furthermore, the same surgical team published a more recent updated study including 316 patients demonstrating survival and freedom from reoperation rates in 10 years as $92 \%$ and $81 \%$, respectively ${ }^{[30,31]}$. In our study, there were only five patients with BAV. Three of these patients underwent SCG and aortic valve resuspension, one underwent SCG and aortic valve commisurotomy, and one underwent Yacoub remodelling and aortic valve resuspension. A 43-year-old male patient with SCG and aortic valve resuspension underwent AVR at the $64^{\text {th }}$ postoperative month. The etiology of AR was cuspis prolapsus according to the operating note.

Another disputed subject is MFS. Martens et al. ${ }^{[32]}$ operated 104 patients with MFS by VSARS. They achieved $86 \%$ freedom from reoperation in 10 years and $80 \%$ freedom from reoperation in 20 years. David procedure is recommended instead of Yacoub procedure for patients with MFS, in order to provide annular stabilization and prevent annular dilatation ${ }^{[3,34]}$. In our study, there were seven patients with MFS. Only one patient underwent AVR at the $108^{\text {th }}$ postoperative month. This patient was a 48-year-old male who had undergone urgent surgery due to acute type 1 aortic dissection. Aortic valve resuspension and SCG replacement had been performed as an operation. The preoperative echocardiography revealed $1^{\text {st }}-2^{\text {nd }}$ degree AR with an LVEDD of $5.8 \mathrm{~cm}$. He became symptomatic with $3^{\text {rd }}$ degree of AR and an LVEDD of $7 \mathrm{~cm}$ at the postoperative nineth year and underwent AVR. Considering that his reoperation took place at the age of 57 years, a nine-year period without a mechanical valve and its disadvantages makes the decision to perform valvesparing surgery during the first operation reasonable.

A significant finding of our study following aortic valvesparing surgery, is the favorable values when comparing the preoperative and postoperative EF, LVEDD, and AR data. Monsefi et al. ${ }^{[35]}$ did not find any statistical difference between the preoperative and postoperative EF and LVEDD values. Nevertheless, there was an increase in postoperative EF compared to preoperative values and significant decrease in postoperative LVEDD compared to preoperative values in our study. Furthermore, in the postoperative period, a decrease was observed in AR compared to the preoperative period in the present study.

\section{Limitations}

The retrospective nature of the study and shorter follow-up period compared to other large series are the main limitations of our study. Lower number of patients compared to other studies may be the main reason for no mortality and lower complication rates in the present study. Furthermore, application of annular stabilization in a limited number of patients is another limitation.

\section{CONCLUSION}

AVrand valve-sparing procedures have become an alternative for valve replacement surgery for suitable patients in the last two decades. It is essential that these procedures have also started to appear in the current guidelines. Better understanding of the underlying pathology together with current advances in surgical techniques and long-term follow-up studies in the literature are going to allow for better results to be obtained. According to the European Society of Cardiology 2017 Guidelines, performing valve repair and valve-sparing procedures in young patients with aortic root dilatation is a class I indication. When we take a look at our last 20 years of experience in aortic valve-sparing procedures, there was no mortality during follow-up and the rates of freedom from reoperation in one, two, and five years were $97.9 \%, 93.6 \%$, and $81 \%$, respectively. In addition, freedom from mid-severe AR in five years was $70 \%$. Only eight (7.4\%) patients underwent AVR during follow-up. In conclusion, when considering the favourable postoperative echocardiographic findings, we believe that one should perform valve-sparing procedures for appropriate patients.

\section{No financial support. \\ No conflict of interest.}




\section{Authors' roles \& responsibilities}

GY

Substantial contributions to the conception or design of the work; or the acquisition, analysis, or interpretation of data for the work; drafting the work or revising it critically for important intellectual content; agreement to be accountable for all aspects of the work in ensuring that questions related to the accuracy or integrity of any part of the work are appropriately investigated and resolved; final approval of the version to be published

AÖ Substantial contributions to the conception or design of the work; or the acquisition, analysis, or interpretation of data for the work; drafting the work or revising it critically for important intellectual content; agreement to be accountable for all aspects of the work in ensuring that questions related to the accuracy or integrity of any part of the work are appropriately investigated and resolved; final approval of the version to be published

FÇ Substantial contributions to the conception or design of the work; or the acquisition, analysis, or interpretation of data for the work; drafting the work or revising it critically for important intellectual content; agreement to be accountable for all aspects of the work in ensuring that questions related to the accuracy or integrity of any part of the work are appropriately investigated and resolved; final approval of the version to be published

EUÜ Substantial contributions to the conception or design of the work; or the acquisition, analysis, or interpretation of data for the work; drafting the work or revising it critically for important intellectual content; agreement to be accountable for all aspects of the work in ensuring that questions related to the accuracy or integrity of any part of the work are appropriately investigated and resolved; final approval of the version to be published

$\mathrm{HZI} \quad$ Substantial contributions to the conception or design of the work; or the acquisition, analysis, or interpretation of data for the work; drafting the work or revising it critically for important intellectual content; agreement to be accountable for all aspects of the work in ensuring that questions related to the accuracy or integrity of any part of the work are appropriately investigated and resolved; final approval of the version to be published

CLB Substantial contributions to the conception or design of the work; or the acquisition, analysis, or interpretation of data for the work; drafting the work or revising it critically for important intellectual content; agreement to be accountable for all aspects of the work in ensuring that questions related to the accuracy or integrity of any part of the work are appropriately investigated and resolved; final approval of the version to be published

Substantial contributions to the conception or design of the work; or the acquisition, analysis, or interpretation of data for the work; drafting the work or revising it critically for important intellectual content; agreement to be accountable for all aspects of the work in ensuring that questions related to the accuracy or integrity of any part of the work are appropriately investigated and resolved; final approval of the version to be published

\section{REFERENCES}

1. Bentall H, De Bono A. A technique for complete replacement of the ascending aorta. Thorax. 1968;23(4):338-9. doi:10.1136/thx.23.4.338.
2. Misawa Y. Valve-related complications after mechanical heart valve implantation. Surg Today. 2015;45(10):1205-9. doi:10.1007/s00595014-1104-0.

3. Oxenham H, Bloomfield P, Wheatley DJ, Lee RJ, Cunningham J, Prescott $\mathrm{RJ}$, et al. Twenty year comparison of a Bjork-Shiley mechanical heart valve with porcine bioprostheses. Heart. 2003;89(7):715-21. doi:10.1136/ heart.89.7.715.

4. Cabrol C, Pavie A, Gandjbakhch I, Villemot JP, Guiraudon G, Laughlin L, et al. Complete replacement of the ascending aorta with reimplantation of the coronary arteries: new surgical approach. J Thorac Cardiovasc Surg. 1981;81(2):309-15. doi:10.1016/S0022-5223(19)37641-X.

5. Miller DC, Stinson EB, Oyer PE, Moreno-Cabral RJ, Reitz BA, Rossiter $S J$, et al. Concomitant resection of ascending aortic aneurysm and replacement of the aortic valve: operative and long-term results with "conventional" techniques in ninety patients. J Thorac Cardiovasc Surg. 1980;79(3):388-401. doi:10.1016/S0022-5223(19)37948-6.

6. Aicher D, Langer F, Adam O, Tscholl D, Lausberg H, Schäfers HJ. Cusp repair in aortic valve reconstruction: does the technique affect stability? J Thorac Cardiovasc Surg. 2007;134(6):1533-8; discussion 1538-9. doi:10.1016/j.jtcvs.2007.08.023.

7. de Kerchove L, Boodhwani M, Glineur D, Poncelet A, Rubay J, Watremez C, et al. Cusp prolapse repair in trileaflet aortic valves: free margin plication and free margin resuspension techniques. Ann Thorac Surg. 2009;88(2):455-61; discussion 461. doi:10.1016/j.athoracsur.2009.04.064.

8. Asano M, Kunihara T, Aicher D, El Beyrouti H, Rodionycheva S, Schäfers HJ. Mid-term results after sinutubular junction remodelling with aortic cusp repair. Eur J Cardiothorac Surg. 2012;42(6):1010-5. doi:10.1093/ ejcts/ezs 120.

9. Lansac E, Di Centa I, Sleilaty G, Lejeune S, Khelil N, Berrebi A, et al. Longterm results of external aortic ring annuloplasty for aortic valve repair. Eur J Cardiothorac Surg. 2016;50(2):350-60. doi:10.1093/ejcts/ezw070.

10. Settepani F, Bergonzini M, Barbone A, Citterio E, Basciu A, Ornaghi D, et al. Reimplantation valve-sparing aortic root replacement with the Valsalva graft: what have we learnt after 100 cases? Interact Cardiovasc Thorac Surg. 2009;9(1):113-6. doi:10.1510/icvts.2009.202622.

11. Schäfers HJ, Aicher D, Langer F. Correction of leaflet prolapse in valve-preserving aortic replacement: pushing the limits? Ann Thorac Surg. 2002;74(5):S1762-4; discussion S1792-9. doi:10.1016/s00034975(02)04136-x.

12. Langer F, Aicher D, Kissinger $A$, Wendler $O$, Lausberg $H$, Fries $R$, et al. Aortic valve repair using a differentiated surgical strategy. Circulation. 2004;110(11 Suppl 1):I167-73. doi:10.1161/01.CIR.0000138383.01283.b8.

13. Aicher D, Schneider U, Schmied W, Kunihara T, Tochii M, Schäfers HJ. Early results with annular support in reconstruction of the bicuspid aortic valve. JThorac Cardiovasc Surg. 2013;145(3 Suppl):S30-4. doi:10.1016/j. jtcvs.2012.11.059.

14. Lillehei CW. The society lecture. European society for cardiovascular surgery meeting, Montpellier, France, September 1992. The birth of open-heart surgery: then the golden years. Cardiovasc Surg. 1994;2(3):308-17. Erratum in: Cardiovasc Surg 1994;2(5):566. doi:10.1177/096721099400200303.

15. De Bakey ME, Cooley DA. Successful resection of aneurysm of thoracic aorta and replacement by graft. J Am Med Assoc. 1953;152(8):673-6. doi:10.1001/jama.1953.03690080017005.

16. Cooley DA, De Bakey ME. Resection of entire ascending aorta in fusiform aneurysm using cardiac bypass. J Am Med Assoc. 1956;162(12):1158-9. doi:10.1001/jama.1956.72970290003013a.

17. David TE, Feindel CM, Webb GD, Colman JM, Armstrong S, Maganti M. Long-term results of aortic valve-sparing operations for aortic root aneurysm. JThorac Cardiovasc Surg. 2006;132(2):347-54. doi:10.1016/j. jtcvs.2006.03.053.

18. Shrestha M, Baraki H, Maeding I, Fitzner S, Sarikouch S, Khaladj N, et al. 
Long-term results after aortic valve-sparing operation (David I). Eur J Cardiothorac Surg. 2012;41(1):56-61; discussion 61-2. doi:10.1016/j. ejcts.2011.04.012.

19. Kvitting JP, Kari FA, Fischbein MP, Liang DH, Beraud AS, Stephens EH, et al. David valve-sparing aortic root replacement: equivalent midterm outcome for different valve types with or without connective tissue disorder. JThorac Cardiovasc Surg. 2013;145(1):117-26, 127.e1-5; discussion 126-7. doi:10.1016/j.jtcvs.2012.09.013.

20. Jeanmart H, de Kerchove L, Glineur D, Goffinet JM, Rougui I, Van Dyck M, et al. Aortic valve repair: the functional approach to leaflet prolapse and valve-sparing surgery. Ann Thorac Surg. 2007:83(2):S746-51; discussion S785-90. doi:10.1016/j.athoracsur.2006.10.089.

21. David TE, Maganti M, Armstrong S. Aortic root aneurysm: principles of repair and long-term follow-up. J Thorac Cardiovasc Surg. 2010;140(6 Suppl):S14-9; discussion S45-51. doi:10.1016/j.jtcvs.2010.07.041.

22. Oka T, Okita Y, Matsumori M, Okada K, Minami H, Munakata H, et al. Aortic regurgitation after valve-sparing aortic root replacement: modes of failure. Ann Thorac Surg. 2011;92(5):1639-44. doi:10.1016/j. athoracsur.2011.06.080.

23. David TE, Armstrong S, Manlhiot C, McCrindle BW, Feindel CM. Longterm results of aortic root repair using the reimplantation technique. J Thorac Cardiovasc Surg. 2013;145(3 Suppl):S22-5. doi:10.1016/j. jtcvs.2012.11.075.

24. Coselli JS, Hughes MS, Green SY, Price MD, Zarda S, de la Cruz Kl, et al. Valve-sparing aortic root replacement: early and midterm outcomes in 83 patients. Ann Thorac Surg. 2014;97(4):1267-73; discussion 1273-4. doi:10.1016/j.athoracsur.2013.10.076.

25. Kunihara T, Aicher D, Rodionycheva S, Groesdonk HV, Langer F, Sata $\mathrm{F}$, et al. Preoperative aortic root geometry and postoperative cusp configuration primarily determine long-term outcome after valvepreserving aortic root repair. JThorac Cardiovasc Surg. 2012;143(6):138995. doi:10.1016/j.jtcvs.2011.07.036.

26. Leontyev S, Trommer C, Subramanian S, Lehmann S, Dmitrieva Y, Misfeld $M$, et al. The outcome after aortic valve-sparing (David) operation in 179 patients: a single-centre experience. Eur J Cardiothorac Surg. 2012;42(2):261-6; discussion 266-7. doi:10.1093/ejcts/ezs011.

27. David TE. Aortic valve sparing operations: outcomes at 20 years. Ann Cardiothorac Surg. 2013;2(1):24-9. doi:10.3978/j.issn.2225319X.2012.11.15.

28. Richardt D, Stierle U, Sievers HH. Long-term results after aortic valvesparing-reimplantation operation (David) in bicuspid aortic valve. J Heart Valve Dis. 2015;24(1):4-9.

29. Shrestha ML, Beckmann E, Abd Alhadi F, Krueger H, Meyer-Bockenkamp F, Bertele S, et al. Elective David I procedure has excellent long-term results: 20-year single-center experience. Ann Thorac Surg. 2018;105(3):731-8. doi:10.1016/j.athoracsur.2017.08.040.

30. Schäfers HJ, Aicher D, Langer F, Lausberg HF. Preservation of the bicuspid aortic valve. Ann Thorac Surg. 2007;83(2):S740-5; discussion S785-90. doi:10.1016/j.athoracsur.2006.11.017.

31. Aicher D, Kunihara T, Abou Issa O, Brittner B, Gräber S, Schäfers HJ. Valve configuration determines long-term results after repair of the bicuspid aortic valve. Circulation. 2011;123(2):178-85. doi:10.1161/ CIRCULATIONAHA.109.934679.

32. Martens A, Beckmann E, Kaufeld T, Fleissner F, Neuser J, Korte W, et al. Valve-sparing aortic root replacement (David I procedure) in Marfan disease: single-centre 20-year experience in more than 100 patientst. Eur J Cardiothorac Surg. 2019;55(3):476-83. doi:10.1093/ejcts/ezy300.

33. Tian D, Rahnavardi M, Yan TD. Aortic valve sparing operations in aortic root aneurysms: remodeling or reimplantation? Ann Cardiothorac Surg. 2013;2(1):44-52. doi:10.3978/j.issn.2225-319X.2013.01.14.

34. Kremer J, Farag M, Zaradzki M, Szabó G, Ruhparwar A, Kallenbach K, et al. The reimplantation valve-sparing aortic root replacement technique for patients with Marfan syndrome: a single-center experience. Sci Rep. 2019;9(1):12021. doi:10.1038/s41598-019-48572-9.

35. Monsefi N, Zierer A, Risteski P, Primbs P, Miskovic A, Karimian-Tabrizi A, et al. Long-term results of aortic valve resuspension in patients with aortic valve insufficiency and aortic root aneurysm. Interact Cardiovasc Thorac Surg. 2014;18(4):432-7. doi:10.1093/icvts/ivt530. 